\title{
Sueño y Vigilia: El Despertar de una Conciencia
}

\section{(En Libro de Manuel, de J. Cortázar)}

En la página 101 de Libro de Manuel ${ }^{1}$ Andrés Fava sueña con algo que prefigura oscuramente su destino. El sueño es narrado desde el recuerdo de la vigilia. Relatándolo, Andrés se da cuenta de que la escena central ha sido suprimida. El resto de la novela hasta la llegada de Andres a Verrières es, en cierto sentido, la búsqueda de esa imagen censurada. Cabe referir el sueño, aunque resumidamente: Andrés va al cine con un amigo incógnito, a quien luego pierde de vista. La película es un thriller de Fritz Lang, cuyo nombre ignora o ha olvidado. En un determinado momento, un camarero de chaqueta blanca se le acerca y le ordena que lo acompañe. Salen del cine y cruzan una sala tras otra mientras el camarero le explica que hay un cubano que lo quiere ver. Andrés entra en un salón a oscuras y se acerca al cubano, pero justo ahí la escena se corta y lo que sigue es Andrés saliendo del salón y volviendo al cine. Sabe que el cubano le ha dicho algo y que tiene una misión que cumplir, pero al mismo tiempo ignora cuál es la misión y no tiene conciencia de la entrevista. En otras palabras, se ha desdoblado, está "actuando a la vez como por dentro y por fuera del film de Fritz Lang o de cualquier film de misterio", es "simultáneamente el film y el espectador del film".

A partir de esa noche, en su desarrollo espiritual Andrés está cumpliendo su misión, pero ni el lector lo sabe con certeza ni él mismo lo sospecha, aunque por momentos intuye que fuerzas oscuras e interiores lo impelen hacia un reencuentro con la "mancha negra", que es la escena desaparecida del sueño. Ese "rendez-vous" le dará una conciencia clara de la naturaleza de su misión, pero no podrá tomar lugar hasta que Andrés no haya llevado a cabo la misión; es decir que las leyes de la causalidad se han invertido. Tal inversión trae ecos de un ensayo de Borges titulado "La Flor de Coleridge". ${ }^{2}$ Dicho trabajo presenta tres

1 Julio Cortázar, Libro de Manuel(Buenos Aires: Editorial Sudamericana, 1973).

2 En Otras Inquisiciones (Buenos Aires: Emecé Editores, 1960). 
modelos literarios de juegos con el tiempo, el último de los cuales se aproxima bastante a la función del sueño de Andrés en esta novela. Se trata de la obra de Henry James The Sense of the Past, cuyo protagonista, Ralph Pendrel, fascinado por un retrato del siglo XVIII, logra trasladarse a la época y el lugar en que el retrato fue hecho. Entre otras personas encuentra al pintor, quien lo pinta, con lo cual se hace evidente en ese momento que el viaje de Pendrel al pasado era requerido para que el retrato existiera. James ha creado así una inversión perfecta de causa y efecto, en que la existencia de un suceso pasado depende de un suceso futuro. El sueño de Andrés espejea, aunque imperfectamente, el sueño de James. Andrés ha tenido una entrevista misteriosa y consecuentemente seguirá un curso de acción que, sin que él lo anticipe, le dará la clave de la entrevista. Así como Ralph Pendrel tiene que viajar al pasado para que el retrato pueda existir, Andrés Fava tiene que cumplir en un futuro incierto la misión oscuramente legada por el cubano para que la mancha negra se materialice. El despertar de su conciencia debe llevarse a cabo para traer el conocimiento de la entrevista en que el cubano le decia únicamente: -Despiértate. Aunque en ambos modelos el efecto debe existir como anterior a la causa, cabe notar la diferencia fundamental entre el sueño de Andrés, en que la supresión de la escena es un ardid sicológico, una censura de la vigilia que algún acto clave logrará derrotar, y la novela de James, que es un relato fantástico en donde el viaje de Pendrel al pasado es la causa del retrato.

La relación del film de Fritz Lang con el sueño en que aparece es bastante compleja. Como el hombre del sillón verde en el cuento de Cortázar "Continuidad de los parques", ${ }^{3}$ la película de Fritz Lang forma parte del sueño de Andrés, pero este último a su vez participa de la película y la completa. En el cuento, un hombre lee una novela cuyo desenlace es su propia muerte. En nuestra novela, Andrés sueña que va al cine y, en medio de la película, se ve "metido en un lío típicamente cinematográfico". El texto sugiere que la entrevista con el cubano es parte de la película ("la escena se corta cuando me acerco al hombre que me espera"), y el desenlace de la novela es la revelación de esa escena misteriosa. Ese descubrimiento efectúa una confluencia de sueño y vigilia. El sueño se completa en la vigilia - en este caso, la decisión de Andrés de acudir a Verrières -, ya que dicha decision precipita el recuerdo de la escena censurada. El final del cuento obedece a un proceso similar. La novela que lee el hombre del sillón verde, una forma de sueño, desborda en la realidad diurna del hombre. El modelo de estos dos instantes es "la flor de Coleridge", un relato minúsculo reproducido de la siguiente forma en el ensayo de Borges que lleva el mismo nombre: "Si un hombre atravesara el Paraíso en un sueño, y le dieran una flor como prueba de que había estado allí, y si al despertar encontrara esa flor en su mano...entonces, qué?" 4

3 .En Final del Juego (Buenos Aires: Editorial Sudamericana, 1969).

4 Otras Inquisiciones. 
Una última nota al respecto. En su sueño, Andrés soslaya el título del film, y no llega a nombrarlo. En 1948 Fritz Lang hizo una película titulada "The Secret Beyond the Door." Este detalle periférico crea un vínculo más entre la imagen misteriosa del sueño y la película de misterio que Andrés mira. El secreto más allá de la puerta es la clave de ambos.

Libro de Manuel es, por sobre todo, una novela de violencia. Violencia a las estructuras que gobiernan y limitan nuestras percepciones, ya sea a nivel lingüístico, político, sexual o novelístico. La forma de destrucción o reestructuración que cabe señalar aquí es aquella que proporcionan los sueños, ya que éstos reiteran noche tras noche su amenaza y desafío a los esquemas diurnos. Mediante la abolición de las coordenadas espacio-tiempo, posibilitan percepciones de la realidad desde otros planos. La imaginación y el desorden, aliados de los sueños, construyen mundos imposibles, nos invitan a pasar al "otro lado" de las cosas. Ese sabotaje a la lógica, esa irrupción natural del absurdo son también los síntomas principales de la locura. En uno de los capítulos de la tercera, hieráticà sección de Rayuela, Horacio Oliveira comenta lo siguiente:

Hablando de los sueños, nos dimos cuenta casi al mismo tiempo que ciertas estructuras soñadas serían formas corrientes de locura a poco que continuaran en la vigilia. Soñando nos es dado ejercitar gratis nuestra aptitud para la locura. Sospechamos al mismo tiempo que toda locura es un sueño que se fija. Sabiduría del pueblo: 'Es un pobre loco, un soñador...'

La correlación es deliberada. En Libro de Manuel el sueño reemplaza a la locura como medio de creación y liberación. Ya en Rayuela una de las preocupaciones mayores del autor era la diaria derrota matutina de los sueños frente a "las defensas de la vigilia." Una frase repetida enigmáticamente soslayaba el ideal: "...alguien decía que las horas del sueño y la vigilia no se habían fundido todavía en la unidad." "Esa posibilidad-insinuada en una novela anterior - es la meta a la cual se encamina Andrés, y de la que hablaremos más adelante.

La dialéctica entre sueño y vigilia se desarrolla contiguamente a otra dialéctica especular a ella: noche y día. Desde el sueño hasta el desenlace de la novela en Verrières, todos los momentos que denotan apertura hacia otra cosa, hacia una posible liberación, toman lugar bajo las sombras de la noche. El día devuelve las cosas a su contexto habitual y restablece el mandato de la costumbre. En sus vagabundeos por París, ligados siempre a sus crisis metafísicas, Andrés alterna entre el orden y el desorden o, metafóricamente, entre la vigilia y el sueño. En su mundo parisiense estos dos polos son sus dos

5 Julio Cortázar, Rayuela (Buenos Aires: Sudamericana, 1972), pp. 455-456.

$6 \quad$ Ibid., p. 383. 
mujeres: Francine, la portaestandarte, acaso demasiado evidente, de la cultura occidental burguesa, y Ludmilla, un espíritu libre y puro que desbarata, sin siquiera saberlo, todos los esquemas convencionales que Andrés rechaza intelectualmente, acatándolos a su vez, en Francine:

A Mí me parecía evidente,...sobre todo después del sueño de Fritz Lang que de alguna manera absolutamente incomprensible era al mismo tiempo una forma diferente y oscura de ese callejón sin salida pero con el doble nombre de Ludmilla y Francine. (p. 166)

Desde el punto de vista del desarrollo de Andrés en la novela, el triángulo Ludmilla-Andrés-Francine es la figura central. Aunque en el momento final Andrés destruye irremisiblemente su vínculo con Francine y opta por una Ludmilla que ya le está vedada, su ideal es poder abarcar los mundos de las dos mujeres y fundirlos, cosa que la escena culminante de Verrières expresa en términos de una unidad de sueño y vigilia. En la época en que ambas mujeres aún son suyas, Andrés reflexiona en una de sus autocríticas frecuentes:

Así diariamente y por supuesto el superyó vigilante, la superestructura de lo diurno instalándose a codazos, el hombre a caballo sobre el techo tratando de abarcar el mundo Ludmilla y el mundo Francine...hasta tocar alguna vez con la mano del más extremo deseo un mundo Ludmilla Francine... (p. 167)

Andrés se desplaza por un París de sueño como un náufrago a la deriva. Sus vagabundeos, regidos por impulsos oscuros, le muestran zonas de la ciudad-el salón de muñecas, el "strip-tease" de madame Antinéa, el Hotel Terrass -, que serán puntos claves en el proceso de definición del portagonista y en el cumplimiento de su misión. Es como si la ciudad fuera cómplice de su sueño y agente de su resolución. Los viajes de Andrés por los laberintos de París son también los viajes de Andrés por su conciencia. Basta examinar el medio de transporte elegido por el protagonista. El metro, sigiloso y subterráneo, extiende sus telarañas por debajo de la piel de París y, en un espejeo perfecto, no es sólo metáfora sino externalización de aquellas fuerzas subliminares que impulsan a Andrés hacia un encuentro con la mancha negra de su sueño:

Y así una vez más cualquier boca de metro...me propondrá por asociación fonética, vagamente mágica, una estación todavía desconocida donde nacerá otro rumbo de la infinita alfombra de París, otra casilla del misterio, otros azares. Por lo demás esa noción un tanto lúgubre que me impulsa desde hace tiempo a perderme en la ciudad...se va traduciendo en descubrimientos curiosos, acordados sordamente con el estado de ánimo que me sirve de compás. (pp. 134-135)

Esta cita postularía una realidad que fuera como una suma infinita de percepciones, una "infinita alfombra" a la manera de los laberintos insolubles que sus autores, legendarios monarcas persas, bordaron en tapices exquisitos. Pero ciertas filosofías orientales proponen, asimismo, como el método más 
perfecto de desentrañar un misterio, el abrirse incondicionalmente al azar. En la novela los viajes caprichosos de Andrés por las redes del metro se dan como una progresión finita que culmina en la estación Antony y eventualmente en Verrières, la última casilla del misterio. La salida del metro en la estación final, descrita en términos de incepción y concepción, refleja su significado de apertura, de nacimiento, y soslaya el despertar político de Andrés:

...eyaculado por fin sin el menor placer en la estación de Antony junto con otros centenares de espermatozoides precipitándose a fecundar el cotidiano huevo del túnel de salida, asomando a una región ignorada del gran París. (p. 349)

Una poesía recitada por Andrés ante Francine la última noche que comparten, reúne ecos del sueño con alusiones veladas a los viajes en metro del protagonista: y su correspondencia a la crisis de conciencia de éste. El poema, que se titula apropiadamente "Maneras de viajar", está impregnado de imágenes surrealistas. Es más, Andrés se refiere a su contenido con la frase "a la vez el tren y alguien perdido en él y que busca a alguien", una metáfora transparente del desdoblamiento del héroe en el sueño (no hay más que sustituir película por tren). La noción de búsqueda, ya definida en esta|mención preliminar caracteriza el poema y apunta al sino de Andrés tal como fuera establecido en su sueño. Pero mientras las frases que se repiten circularmente sugieren una búsqueda interminable, se vislumbra un espacio abierto, una posibilidad de llegar al encuentro deseado:

Taxi y hotel hasta la hora

del tren, wagon-lit

(el 9, el 34, el 5?)

donde quizá se encuentren

para la última etapa (p. 259)

Hay en estas líneas dos referencias dignas de señalar, ya que juntas vinculan el sueño de Andrés con la decisión del protagonista de viajar a Verrières. En primer lugar, los últimos renglones nos devuelven a la escena en que Andrés relata su sueño por primera vez y soslaya "una acción misteriosa que sólo se explicará al final." Asimismo, esta sección de la poesía prefigura lo que aún está por ocurrir: la violación de Francine por Andrés en el Hotel Terrass, el tren que lo conducirá a Verrières y el "rendez-vous" final con la mancha negra del sueño. Unas líneas dentro de una poesía arrojan flechas hacia momentos pasados y futuros de la novela, poniendo en relieve el movimiento circular que esos momentos trazan entre sí: del sueño a Verrières y de vuelta al sueño.

Entre las incrustaciones en la sección hierática de Rayuela hay una poesía monótona pero alucinante de Octavio Paz. Las últimas diez líneas del poema de Cortázar llaman la atención, por su semejanza, a esos versos incrustados: la misma repetición de frases inconclusas, el mismo tono de navegante perdido, ya sea en la penumbra de un tren nocturno o en el silencio sordo de la niebla, las mismas espirales infinitas. Vinculados por su contigüidad relativa en la obra del 
mismo autor, las dos poesías se enriquecen mutuamente. Otro modelo externo del verso en cuestión es un sueño, relatado por Anaïs Nin en Winter of Artifice y reproducido asimismo en la última sección de Rayuela.

El sueño estaba compuesto como una torre formada por capas sin fin que se alzaran y se perdieran en el infinito o bajaran en círculos perdiéndose en las entrañas de la tierra. Cuando me arrastró en sus ondas, la espiral comenzó, y esa espiral era un laberinto. No había techo ni fondo, ni paredes ni regreso. Pero había temas que se repetían con exactitud. 7

Por lo demás, los pasillos del tren en la poesía son a la vez ecos de los pasajes subterráneos del metro y del territorio interior de Andrés. La estación sin nombre, el rechazo en cada puerta, evocan las zonas de la conciencia del protagonista, vedadas hasta a él mismo y que él deberá sacar a luz. Este poema aparece recién al comienzo de la larga noche de Andrés y Francine. La imagen suprimida del sueño es aún una mancha negra inapresable, que los sucesos de esa noche se encargarán de disipar.

Todos los actos cometidos por Andrés esa noche parten de la necesidad de recobrar la escena perdida del sueño. Pero el ultraje de Francine se presenta, más que cualquier otro, como una tentativa consciente de acabar con la mancha negra en otra de sus manifestaciones. La "censura repugnante" del sueño-la supresión de la escena con el cubano-equivale a la censura sexual que Francine opone constantemente a los intentos de experimentación de Andrés. Es decir que esa escena soñada ha desaparecido en lo que el soñador califica de "un olvido de mentira", creado por los esquemas lógicos de la vigilia a fin de impedir la infiltración de percepciones e imaginaciones nocturnas en su propia interpretación limitada de la realidad. Un conflicto interior de naturaleza semejante toma lugar en Francine; sus valores éticos, su educación religiosa, "lentas instilaciones de infancia y pubertad,...una verdad creciendo en tierra de mentiras genealógicas", le impiden aceptar una violación de su cuerpo, tanto menos cuando se trata de aquella travestía de la ortodoxia sexual que es el legado de Sodoma. Andrés es una fuerza liberadora, pero más aún que de la liberación de Francine, se trata de la suya. A esta altura de la novela ya se ha establecido que esta noche es cara o cruz; están asistiendo "a la muerte de un pequeño burgués o a su confirmación." Andrés se siente al borde de otra posible realidad que anulará la zona de carencia que es la mancha negra de Fritz Lang. El rechazo de Francine es otra mancha negra, "la alambrada entre la posible realidad y Francine." Debe vejar a Francine porque en esa violación hay un pasaje, especialmente ahora que el obstáculo-la censura - se define tan claramente: "sentimiento de haber llegado al borde justamente cuando Francine se replegaba negándose, se arqueaba cimbreándose." A Andrés lo impulsa no sólo el peso de su sueño sino también la conciencia de su pasado, "la Joda soslayada" y perdida tantas veces, y sobre todo el remordimiento de que Ludmilla haya cruzado el puente, y que lo haya 
hecho sola. Una vez más las dos mujeres son los polos opuestos que, ya sea por sí mismas o por los valores que representan, precipitan las decisiones de Andrés quien, habiendo roto ritualmente su relación con Francine, va en busca de una Ludmilla que ya pertenece a otro hombre.

El recuerdo de la escena censurada del sueño entre los cedros de Verrières coincide con el despertar político de Andrés y lo refleja. La orden imperiosa del cubano se hace oir en la memoria del héroe en el momento preciso en que éste está dispuesto a acatar el llamado de su conciencia, a precio de sus previas costumbres solitarias:

Ya voy, mi amigo

espere a que termine Joni Mitchell

que se calle Atahualpa, estoy llegando,

abrí, Ludmilla, que me esperan

en una pieza a oscuras. (p. 354)

La vigilia y el sueño se funden finalmente, como lo prueba la poesía que precede a la visión de Andrés, en una percepción continua de la realidad, sin la rigidez de los esquemas diurnos que hacen necesario - a la vez reprimiéndolo cada mañana-el vuelo nocturno de una imaginación liberada. La "pieza a oscuras" a la cual se aproxima el protagonista es simultáneamente el cuarto en que lo espera el cubano y la casa que sirve de escondite a los miembros de la Joda. El vestigio de un sueño se confunde con un suceso externo de vigilia.

Ahora que la misión de Andrés ha sido cumplida se demuestra la complejidad de la censura del sueño y su razón de ser. Al igual que Andrés, el lector descubre algo que tendría que haber sido obvio desde el comienzo. En el plano ideal de la novela, el olvido de la escena con el cubano fue obra de las defensas de la vigilia. En el plano de la relación entre autor y lector, entre Julio Cortázar y nosotros, la razón de la censura es de índole estratégica. En el momento de la novela en que el sueño ocurre, Andrés no está aún capacitado - no ha sufrido los cambios necesarios - para comprender plenamente las implicaciones de alguien que le dice: -Despiértate. Una conciencia total del sueño sería incomprensible para Andrés e inadmisible para el lector, ya que su resultado sería eliminar el suspenso. Así es que Andrés debe olvidar esa escena de su sueño y el lector la tiene que ignorar por completo, de modo que las alusiones a un misterio cuya clave está en el final, en su resolución, estén dirigidas no solo hacia Andrés-en el plano de una novela que enmascara su ficcionalidad-sino también hacia el lector a nivel de obra consciente de su propia ficción. Esta duplicidad recién se descubre en el momento en que Andrés recuerda su sueño. La epifanía del protagonista es también la revelación del lector. El autor logra en esa escena una fusión exquisita de sueño y vigilia, pero a dos niveles: entre un proceso interior de un personaje (el sueño de Andrés) y su resultado externo que lo espejea (la llegada a Verrières), y entre la experiencia de un ente ficticio y aquélla del lector.

La función de Ludmilla como intercesora entre Andrés y la Joda, especialmente su referencia como tal en la poesía ("abrí, Ludmilla, que me 
esperan/ en una pieza a oscuras"), evoca la figura del camarero en el sueño, delineando aun más su desbordamiento en la vigilia. Es más, la misma poesía postula una cita doble para el protagonista, con otro personaje de la novela y con una imagen de sueño: "saber que llegaré a una cita/ con nadie, con mujer que es de otro/ con alguien que me habló en la sombra." Con esta convergencia de planos se enriquece la función del sueño de Andrés en la novela. Se ha cerrado el círculo entre el sueño en sú narración inicial, y su reconstrucción frente al chalet en Verrières inmiscuyendo profundamente, no sólo a los personajes pertinentes sino también al lector. El recuerdo de la mancha negra pone término al misterio, pero a modo de compensación el lector puede gozar, a partir de ese instante de la trama, de un conocimiento más amplio de la estructura esqueletal de la obra. 